\title{
CONTEXTUALISM, RELATIVISM, AND FACTIVITY.
}

\section{ANALYZING 'KNOWLEDGE' AFTER THE NEW LINGUISTIC TURN IN EPISTEMOLOGY}

ELKE BRENDEL

University of Mainz

\section{INTRODUCTION}

Linguistic analysis provides a methodological instrument of utmost importance for theory-formation in contemporary epistemology. Peter Ludlow recently declared a "new linguistic turn in epistemology" that shares with the traditional "linguistic turn" the idea that linguistic analysis is important for assessing the correctness of epistemic positions, but is less ambitious than the traditional "linguistic turn" with regard to its goals: "We are not looking for quick solutions to (or dissolutions of) long-standing philosophical concerns about issues like scepticism, but rather we are looking at linguistic theory to help us probe specific components of more complex and subtle epistemological theories." One example of this "new linguistic turn" in epistemology is the discussion about the plausibility of the contextsensitivity of knowledge ascriptions. In the following, I will assess the debate about contextualist accounts of knowledge with regard to their linguistic plausibility and logical correctness. I will show that contextualism is wrong in explaining the context-sensitivity of "know" in analogy to indexical terms such as gradable or scalar predicates. In analyzing the disanalogies between "know" and other indexical terms certain peculiarities of the context-sensitivity of "know" will become apparent that give rise to a new semantics of knowledge ascriptions. This new semantic approach of "informed contextualism" is superior to standard contextualism as well as to relativism. It can account for both, the variability of the semantic content of a knowledge ascription across contexts and for the phenomenon that we

${ }^{1}$ Ludlow (2005), p.12. 
tend to retract earlier knowledge claims when standards rise. In contrast to a relativist assessment-sensitive semantics for "know", the proposed semantics can also account for the apparent asymmetry between the raising and the lowering of epistemic standards. Furthermore, it can resolve the factivity problem for knowledge.

\section{Case Studies in Favour of Contextualism}

Contextualists appeal to both, linguistic intuitions concerning the truthconditions of knowledge-attributing (and knowledge-denying) sentences and to data of linguistic theories concerning context-dependency of language, in order to attain a satisfying semantic theory of "know". They also claim that linguistic research into the semantics of knowledge attributions can provide a key to resolving some of the notorious problems with regard to knowledge, such as scepticism.

According to contextualists such as Stewart Cohen, Keith DeRose and David Lewis, the truth-conditions of sentences of the form " $S$ knows that $p$ " are determined in part by certain context-dependent standards of the speaker, i.e., the knowledge-ascriber. ${ }^{2}$ In particular, the standards are determined by error-possibilities that are salient in the context of the speaker. The sentence " $S$ knows that $p$ " is true in a context $c$ only if $S$ meets the standards for knowledge in $c$, i.e., if $S$ 's epistemic situation allows her to rule out all error-possibilities to $p$ that are salient in $c$. So, if $S$ 's epistemic situation does not allow $S$ to rule out these error-possibilities, the sentence " $S$ knows that $p$ " is false in this specific context $c$, even if $p$ turns out to be true. As a result, depending on the standards that are operant in the context of the knowledge-ascriber, the same sentence " $S$ knows that $p$ " can be true in one context and false in a different, more stringent context. This contextdependency of knowledge-attributing sentences seems to be strongly supported by our linguistic intuitions concerning many case studies that contextualists present.

Among the most prominent examples in favor of contextualist intuitions are certain variants on Fred Dretske's famous "zebra-example": ${ }^{3}$ Let us assume that Christian and Markus are on a zoo visit. They stop at a paddock with black and white striped animals. Markus, after looking at one of

\footnotetext{
${ }^{2}$ See, for example, Cohen (1986, 1988, 1998, 2000, 2004), DeRose (1992, 1995, 1999, 2005), and Lewis (1979, 1996).
}

${ }^{3}$ See Dretske (1970), p.1016. 
these animals, immediately identifies it as a zebra. Markus is looking at this animal under normal perceptual conditions and he has a good prior knowledge of what zebras look like. Let us further assume that the animal he is looking at is in fact a zebra. If Christian was asked whether Markus knows that this animal is a zebra, he would without hesitation say "yes". In the given context of a zoo visit, among the relevant error-possibilities that Markus has to rule out in order to know that the animal is a zebra are, for example, the possibilities that the animal is a donkey or a pony. Since Markus can reliably distinguish zebras from donkeys or ponies and since the animal he is looking at is in fact a zebra, Christian's claim that "Markus knows that the animal is a zebra" seems to be perfectly true in this context. But let us now modify Christian's context of knowledge-ascription. Christian has heard a rumour that in order to save money the zoo director adds some cleverly disguised mules that look exactly like zebras. By considering the possibility that the animal Markus is looking at is a disguised mule, the standards for knowledge have been raised compared to the standards operant in the context of the "normal" zoo visit. Since Markus cannot rule out this now salient error-possibility, Christian's claim "Markus does not know that the animal is a zebra" also seems to be perfectly true in this higher standards context.

Contextualists not only claim to provide an account of knowledge that is in accordance with our linguistic intuitions concerning the semantics of knowledge-attributing sentences, they also take the credit for having met the sceptical challenge. Since sceptical hypotheses, such as being a brain in a vat, are not salient in everyday contexts, a person need not rule out the possibility of being a (handless) brain in a vat in order to know that she has hands in such a context. So, in an everyday context, the sentence "Markus knows that he has hands" as well as "Markus knows that he is not a (handless) brain in a vat" can be true. Only if the knowledge-ascriber is contemplating sceptical hypotheses (and thereby raising the standards for knowledge extremely high) do her utterances of "Markus knows that he has hands" and "Markus knows that he is not a brain in a vat" come out false. Thus, one advantage of the contextualist's response to scepticism is that a contextualist can keep a certain contextualized version of epistemic closure: If " $S$ knows that $p$ " is true in context c and if " $S$ knows that $p$ implies $q$ " is true in $c$, then " $S$ knows that $q$ " also turns out to be true in the same context $c$, even if $q$ is the negation of a sceptical hypothesis. According to contextualism, contrary to the radical sceptic's general denial of the possibility of knowledge, most of our positive knowledge-attributing sentences 
can be true. The only concession to the sceptics a contextualist has to make is to admit that in sceptical high standards contexts our positive knowledge-ascriptions are indeed all false.

According to some contextualists, the standards for "know" are not only determined by salient error-possibilities that are operant in the speaker's context, but also by questions of interests and stakes given in the special situation of the knowledge-ascription. DeRose most prominently argues for such a "stake-induced" context determination of knowledgeascribing sentences. Various case studies indicate ${ }^{4}$ that, if a lot hinges on $p$ being true or if we have a vital interest in the truth of $p$, we have the tendency to be more cautious and hesitant in claiming to know that $p-$ compared to cases where not so much is at stake, if $p$ turns out to be false.

The zebra example and other case studies support the general contextualist thesis that the truth-conditions of knowledge-attributing (or knowledge-denying) sentences are context-dependent. Stakes, interests, salient relevant error-possibilities etc. that are given in the context of the knowledge-ascription seem to determine in part the standards for truly or falsely ascribing knowledge to others or to ourselves. However, it is less clear and highly contested which linguistic data about context-sensitivity best explains this certain kind of context-dependency of knowledge-ascriptions.

\section{THE INDEXICALITY OF "KNOW"}

Contextualists usually treat "know" as a certain kind of an indexical. Cohen, in particular, stresses the point that the context-sensitivity of knowledge-ascriptions can be best explained by analogy with gradable or scalar predicates, such as "flat", "bald", "rich", "happy" etc. ${ }^{5}$ As with knowledge ascriptions, the truth-conditions of sentences attributing gradable adjectives to objects can vary with the context of utterance. So for example, the sentence "Peter is tall" can be uttered truly by a speaker who uses the word "tall" in the context of "tall for a first grader". The same sentence can be falsely uttered by a speaker with more stringent standards of tallness (who, for example, uses "tall" in the sense of "tall for a basketball player").

But it has been argued quite convincingly, for example by Jason Stanley, that the analogy between "know" and gradable or scalar predicates, such as "tall", "flat" etc., breaks down on various points. There are

\footnotetext{
${ }^{4}$ See, for example, DeRose's "bank cases" in DeRose (1992), p.913.

${ }^{5}$ Cohen (2000), p.97.
} 
important linguistic dissimilarities between "know" and gradable or scalar predicates. Unlike "tall" or "flat", "know" does not seem to allow for degree modifiers, such as "very", "really", "enough", or for comparative constructions. ${ }^{6}$

There is another crucial difference between gradable or scalar predicates, like "tall", and "know". Raising the standards of gradable predicates does normally not effect the truth-value of sentences in which the predicate is used in lower standards contexts. Even if Markus is in higher standards context in which "tall" means "tall for a NBA player", he could nevertheless truly utter the following sentence (1):

(1) Even if I am now using "tall" in the sense of "tall for a NBA player" (according to which I am not tall), I am still tall for a Western European.

But this does not seem to be true with regard to knowledge-ascriptions. If the fraudulent activities of the zoo director came to Markus's attention, he would surely not claim:

(2) According to ordinary standards contexts, I still know that the animal is a zebra, but in my present higher standards context I do not know that the animal is a zebra,

or

(2)' According to my present higher standards context, I know that I knew that the animal was a zebra when I was in lower standards context.

If a subject learns about relevant error-possibilities to $p$ hitherto ignored, the new higher standards context now seems to be the decisive context that forms the background for self-ascriptions (or denials) of knowledge of $p$. The answer to the question whether her epistemic position allows ruling out all error-possibilities to $p$ in the new higher standards context seems to be the crucial factor for an epistemic subject $S$ in order to decide whether she now knows that $p$ and knew that $p$ all along. As long as $S$ does not have good reasons to ignore the new error-possibilities in the high standards context or does not obtain some new evidence that renders these possibilities irrelevant, it does not seem right of her to claim ordinary stan-

\footnotetext{
${ }^{6}$ See Stanley (2004).
} 
dards (or any other kind of lower standards) knowledge. This is why in the above example Markus will withdraw his earlier knowledge claim and will treat it as false. Rather than claiming (2) or even (2)', he will therefore assert something like the following:

(3) My earlier knowledge claim (in ordinary standards context) "I know that the animal is a zebra" was false. I don't know that the animal is a zebra, and I didn't know it earlier.

\section{The Factivity PRoBlem}

The upshot of my above discussion concerning the semantics of knowledge-attributing (and denying) sentences is that there are crucial differences between "know" and gradable or scalar predicates, such as "tall", "flat" etc. In particular, the alleged analogies break down with regard to ascriptions of knowledge in some low standards context from the perspective of a higher standards context in which the subject no longer knows.

Appealing to pragmatic explanations or to a version of an error theo$r y$ in order to account for the apparent tendency to retract former knowledge claims when standards rise but still treat sentences such as (2) or (2)' as literally true, does not seem to be an attractive manoeuvre for contextualists. It is not the case that these sentences only seem to be incorrect because of some pragmatic features or because speakers are simply mistaken about the correct semantics of knowledge ascriptions. The following factivity problem for contextualism shows that those sentences can even generate an inconsistency at the semantic level of contextualist knowledge ascriptions.

Let " $M$ " refer to Markus, " $p$ " to the proposition that the animal (Markus is looking at) is a zebra, " $c_{L}$ " for the low or ordinary standards context of a "normal" zoo visit, " $c_{H}$ " for the high standards context in which the cleverly disguised mule hypothesis has come to Markus's attention, and " $K\left(x, y, c_{s}\right)$ " stands for the knowledge claim that subject $x$ knows that $y$ according to the standard of knowledge $s$ associated with the context $c$.

We can now state the contextualist insight that Christian's utterance that Markus knows that $p$ is true in low standards context, but not in high standards context by the conjunction of the following claims (a) and (b) ${ }^{7}$ :

${ }^{7}$ For a similar version of the factivity problem for contextualism see Brendel (2003, 2005, 2007). 
(a) $K\left(M, p, c_{L}\right) \wedge$ (b) $\neg K\left(M, p, c_{H}\right)$.

The claim that knowledge (in any context) is factive can be formulated by the following contextualist factivity principle $\left(\right.$ Fact $\left._{\text {context }}\right)$ :

$\left(\right.$ Fact $\left._{\text {context }}\right) K\left(x, y, c_{Z}\right) \rightarrow y$

(for all subjects $x$, propositions $y$, and contexts $\mathrm{c}_{Z}$ ).

As already mentioned, the contextualist embraces a contextualised version of the principle of epistemic closure $\left(\mathrm{Clos}_{\mathrm{context}}\right)$ that can be formalized as follows:

$\left(\mathrm{Clos}_{\text {context }}\right) K\left(x, y_{1}, c_{Z}\right) \wedge K\left(x,\left(y_{1} \rightarrow y_{2}\right), c_{Z}\right) \rightarrow K\left(x, y_{2}, c_{Z}\right)$

(for all subjects $x$, propositions $y_{1}$ and $y_{2}$, and contexts $c_{Z}$ ).

If contextualism is true and if "know" is like a gradable predicate, such as "tall", then Markus should know in high standards context that he knows in low standards context that the animal is a zebra, i.e, he should know in $c_{H}$ that (a):

(i) $K\left(M,(\mathrm{a}), c_{H}\right)$.

Furthermore, a competent speaker who possesses the concept of knowledge, should know that knowledge is factive, i.e., that a subject only knows that $p$, if $p$ is true. It seems to me that a subject should know this conceptual truth of "know" even in very high standards contexts. Even in sceptical contexts in which brains in vats hypotheses are salient, subjects still know that knowledge implies the truth of the known proposition. So, it is fair to claim that Markus knows that knowledge is factive even in $c_{H}$. Thus, in particular, the following claim holds:

(ii) $K\left(M,\left(K\left(M, p, c_{L}\right) \rightarrow p\right), c_{H}\right)$.

But with (i), (ii), and $\left(\mathrm{Clos}_{\text {context }}\right)$, we get $K\left(M, p, c_{H}\right)$ - which contradicts the assumption (b). 


\section{ASSESSMENT SENSITIVITY OF KNOWLEDGE ATtRIBUTIONS AND MACFARLANE'S RELATIVISM}

I have argued that the contextualist linguistic model of "know" is not fully adequate. There are crucial differences between "know" and gradable predicates. That "know" is indeed a very special notion can, in particular, be shown by the factivity problem. In a sense, unlike all the other terms with which "know" is linguistically compared, "know" seems to be a special hybrid concept. On the one hand, due to the factivity of "know", the concept of knowledge has an objective, non-epistemic, and contextinsensitive part. That is why we strongly subscribe to the claim that we do not know that $p$, if $p$ is not true. On the other hand, we have strong contextualist intuitions that indicate that the concept of knowledge also has an epistemic and context-sensitive part. That is why we strongly subscribe to the thesis that we do not know that $p$, if we are not able to meet certain standards that are operant in the context of the knowledge ascription. Relevant error-possibilities, stakes, and interests seem to determine to a great extent whether we attribute or deny knowledge to others and ourselves. Confronted with new and hitherto ignored error-possibilities to $p$ that we render relevant and that we are not able to rule out, we are no longer inclined to claim to know that $p$ in lower standards knowledge in which we were less scrupulous, i.e., as Hawthorne puts it, we tend to regard the higher standards context as the more "enlightened perspective", such that it is almost impossible to lower the standards again. ${ }^{8}$ This is also the reason why we normally do not refer to different contexts or different uses of the verb "know" in order to meet challenges to our knowledge claims posed by someone confronting us with error-possibilities or stakes of which we were previously unaware. If Christian challenges Markus's claim that he knows that the animal is a zebra by confronting him with the facts about the corrupt zoo director, it seems to be extremely inappropriate if Markus tries to reconcile this conflict by clarifying that he was using "know" in lower standards knowledge. The only adequate reaction on Markus's side would be to give reasons why the painted mule hypothesis is not relevant, or simply too far-fetched, or extremely improbable in the present case, or to give in and claim that he doesn't know that the animal is a zebra. "[T]he fact that we have very few devices in ordinary life for implementing the clarification technique when it comes to 'knows'," is as Hawthorne claims, ${ }^{9}$ a

\footnotetext{
${ }^{8}$ Hawthorne (2004), pp.164f.

${ }^{9}$ Hawthorne (2004), p. 105.
} 
good indication of a disanalogy between "know" and other context-sensitive terms.

But how are we to deal with the factivity problem and the other peculiarities of "know" while still adhering to our intuitions concerning the context-sensitivity of knowledge ascriptions?

John MacFarlane has argued for a relativist semantics for "know" according to which "know" is sensitive to the epistemic standards in play at the context of assessment. ${ }^{10}$ MacFarlane's relativism has it that if we assess in a context $c 2$ a knowledge claim made (by others or ourselves) at a different context $c 1$, the epistemic standards relevant for fixing the truthvalue of this knowledge claim are determined by $c 2$. According to MacFarlane, the assessment sensitivity of knowledge claims can explain why we tend to withdraw knowledge attributions made at a lower standards context when assessing them in a higher standards context. Furthermore, assessment sensitivity is even supposed to explain why we claim in a higher standards context that we were wrong in claiming to know in a lower standards context: "We must be prepared to withdraw a knowledge attribution if standards change, even if the subject's epistemic position is just as we thought it was. Relatedly, when we challenge others for having made false knowledge claims, we may be assessing them in light of standards higher than the ones they recognized when they made them."

MacFarlane's relativism seems to provide a resolution of the factivity problem: In the context of assessment $c_{H}$, Markus would deny (a). So, it wouldn't be true in $c_{H}$ that he knows that (a). Since sentence (i) turns out to be false, no factivity problem would get off the ground.

It is nevertheless premature to conclude that assessment sensitivity provides the key to the correct semantics of knowledge attributions. To be sure, MacFarlane's relativism can account for both the apparent fact that the semantics for "know" depends on varying epistemic standards and for the phenomenon that we retract knowledge claims when assessing them in

${ }^{10}$ See MacFarlane (2005). Like contextualists, relativists treat knowledge ascriptions as context sensitive. But relativists disagree with contextualists on the indexicality of "know". Instead of claiming that a sentence of the form " $S$ knows that $p$ " can express different propositions in different contexts, relativists contend that such a sentence expresses a constant proposition but the truth-value of this proposition can vary with a certain circumstantial parameter. This paper is not concerned with the differences between the contextualist's and the relativist's accounts of proposition. Rather, it is the specification of the circumstantial parameter in MacFarlane's relativism, i.e., his assessment sensitivity account of knowledge, that I want to focus on.

${ }^{11}$ MacFarlane (2005), p.231. 
a higher standards context in which hitherto ignored but relevant errorpossibilities arise that our epistemic position does not allow to rule out. As a consequence, a relativist semantics can also deal with the factivity problem. But MacFarlane's relativism does not seem to be perfectly adequate with regard to situations in which the assessor is less informed or more ignorant than the epistemic subject whose knowledge claim is assessed. Let us assume that Markus - after having heard about the criminal activities of the zoo director - claims: "I do not know that this animal is a zebra". Christian, who does not possess this information, assesses Markus's knowledge claim by saying: "Markus was wrong in claiming not to know that the animal is a zebra." According to MacFarlane, Christian's withdrawal of Markus's knowledge claim should be true since the relevant standards that determine the truth-value of Christian's assessment are the standards operant in the context of assessment, i.e., the lower standards in Christian's context. But if the cleverly disguised mule hypothesis is relevant and if there is no counter-evidence to this hypothesis, Christian's withdrawal of Markus's knowledge claim does not seem to be correct. So contrary to MacFarlane's relativism, it seems that the relevant standards are not necessarily those in place at the context of assessment, but those standards operant in the context of the best informed epistemic subject.

MacFarlane's assessment-sensitive semantics for "know" is thus not sensitive enough to the apparent asymmetry between the lowering and the raising of epistemic standards. It seems to be much easier to raise standards by challenging knowledge claims than to lower them again. When standards rise, the truth of an earlier knowledge claim made by an epistemic subject $S$ in a less stringent standards context is challenged. If $S$ 's epistemic situation does not allow $S$ to react to the challenge by ruling out the new error-possibilities that are now salient in the higher standards context, the assessor can now withdraw $S$ 's earlier knowledge attribution and claim that $S$ didn't know then. If $S$ is identical to the assessor, then the assessor withdraws her own knowledge attribution made in a lower standards context. But once the standard is raised and the earlier knowledge attribution is retracted it does not seem to be appropriate to simply lower the standards again and put the earlier knowledge claim back into force. This is, as shown above, the crucial difference between "know" and gradable predicates. Whereas it is relatively easy to switch back and forth between different standards of "tall" or "flat" in different contexts of use, "easy knowledge manoeuvres" by lowering standards of knowledge are in many cases illegitimate. Since knowledge is factive, relevant error-possibilities to $p$ 
hitherto ignored will challenge the truth of $p$ and as such challenge the truth of an earlier knowledge attribution " $S$ knows that $p$ " made in a lower standards context. Unlike MacFarlane who claims, that when standards fall again, speakers "go right back to their old ways, rather than becoming more cautious in attributing knowledge," 12 I find it in many cases intellectually dishonest to lower standards by simply ignoring relevant error-possibilities. Lowering standards is, of course, legitimate if our evidential situation now allows ruling out the error-possibilities that were salient in the higher standards context (if, for example, the rumours about the corrupted zoo director have been proven false), or if we simply deal with a different situation that calls for a laxer epistemic evaluation (if, for example, Markus visits a different zoo where no rumours about a corrupted zoo director circulate and looks at an animal looking like a zebra ...). But as long as there are no good reasons to lower the standards, attributing knowledge instead of refraining from knowledge does not seem to be correct. Similarly, if an assessor is simply ignorant and less informed than the speaker $S$, it is not the assessor's context that determines the truth or falsity of $S$ 's knowledge attribution. Claiming from the ignorant assessor's perspective that $S$ does (and did) know that $p$ (although $S$ 's epistemic situation does not allow to rule out relevant error-possibilities in $S$ 's more "enlightened" context), is incorrect - and a semantics for "know" should account for this fact.

\section{INFORMED CONTEXTUALISM}

I have argued that many case studies that appeal to our linguistic intuitions show that, as a matter of fact, the concept of knowledge has a context-sensitive aspect. Relevant error-possibilities, stakes, interests etc. do seem to determine context-sensitive standards for "know". But I have also tried to show that the contextualist linguistic model for "know" is not completely adequate, since there are crucial differences between "know" and gradable or scalar predicates. These differences become manifest, in particular, in relations to higher knowledge ascriptions of lower knowledge. Treating "know" here on a par with other context-sensitive terms can even lead to a contradiction, as the problem of factivity shows. So, we are in need of a semantics for knowledge ascriptions that accounts for our contextualist intuitions, but still explains our tendency to retract knowledge when standards rise. Furthermore, the semantics for "know" should provide a solu-

${ }^{12}$ MacFarlane (2005), p.231. 
tion to the factivity problem. MacFarlane's assessment-sensitive semantics for "know" seemed to be the right candidate for the correct semantics of knowledge ascriptions, but turned out to be inadequate with regard to contexts of assessment in which the assessor is in a less informed epistemic position than the speaker.

The semantics for "know" I would like to suggest regards "know" as sensitive to the best informed standards context. To have a label for this semantic account, I will call it informed contextualism. In the case where the context of use and the context of assessment of a knowledge ascription coincide, the truth-value assignments in informed contextualism are identical to those in standard contextualism. Consequently, informed contextualism can account for the variability of the semantic content of knowledge ascriptions across contexts. In the case where the context of use and the context of assessment fall apart and the assessor is in a better informed epistemic position than the speaker, the truth-value assignments in informed contextualism are identical to those in MacFarlane's relativism. Consequently, informed contextualism can account for the retraction of knowledge when standards rise. Furthermore, it can resolve the factivity problem since sentence (i) turns out to be false. In the case where the context of use and the context of assessment fall apart and the assessor is in a less informed epistemic position than the speaker, the decisive standards that determine the truth-value of the knowledge ascription are the standards operant in the speaker's context. Consequently, informed contextualism can account for the fact that an unmotivated lowering of epistemic standards cannot turn a former knowledge-denying claim into a true knowledge assertion.

Of course, the proposed account of informed contextualism is in need of further elaboration. In order to develop a full-fledged semantic theory of knowledge attributions, much more has to be said about what counts as "the best informed standards context". If, for example, an epistemic subject $S$ wants to successfully engage in ordinary life (or wants to conduct research into natural sciences), the extremely high standards of a sceptical context are not appropriate - unless there is evidence for the correctness of the sceptical hypothesis (as there was for the Matrix hero Neo). Here it seems correct of $\mathrm{S}$ to withdraw her former refusal to know when she was in a sceptical mood. So, the most sceptical standards context is not always the best informed standards context. The best informed epistemic standards context is the one that is the best warrant for the truth of the proposition that the speaker claims to know. Knowledge is factive after all. MacFar- 
lane contends that "we think of knowledge attributions as temporary record-keeping devices - tools for keeping track of a normative status keyed to ever-changing present circumstances - rather than straightforward statements of facts." 13 If informed contextualism is on the right track, knowledge attributions are closer to statements of facts than MacFarlane thinks.

\section{REFERENCES}

Brendel, Elke (2003): "Was Kontextualisten nicht wissen", Deutsche Zeitschrift für Philosophie 51, pp.1015-1032.

Brendel, Elke (2005): "Why Contextualists Cannot Know They Are Right: Self-Refuting Implications of Contextualism", Acta Analytica 20, pp.38-55.

Brendel, Elke (2007): "Kontextualismus oder Invariantismus? Zur Semantik epistemischer Aussagen", in: A. Rami/H. Wansing (eds.): Referenz und Realität, Paderborn: mentis, pp.11-37.

Cohen, Stewart (1986): "Knowledge and Context", Journal of Philosophy 83, pp.574583.

Cohen, Stewart (1988): "How to be a Fallibilist", Philosophical Perspectives 2, pp.91123.

Cohen, Stewart (1998): "Contextualist Solution to Epistemological Problems: Scepticism, Gettier, and the Lottery", Australasian Journal of Philosophy 76, pp.289306.

Cohen, Stewart (2000): "Contextualism and Skepticism", Philosophical Issues 10, pp.94-107.

Cohen, Stewart (2004): "Knowledge, Assertion, and Practical Reasoning", Philosophical Issues 14: Epistemology, pp.482-491.

DeRose, Keith (1992): "Contextualism and Knowledge Attributions", Philosophy and Phenomenological Research 52, pp.913-929.

DeRose, Keith (1995): "Solving the Sceptical Problem", Philosophical Review 104, pp.1-52.

DeRose, Keith (1999): "Contextualism: An Explanation and Defense", in: J. Greco/ E. Sosa (eds.): Epistemology, Oxford: Basil Blackwell, pp.187-205.

DeRose, Keith (2005): "The Ordinary Language Basis for Contextualism, and the New Invariantism", The Philosophical Quarterly 55, pp.172-198.

Dretske, Fred (1970): "Epistemic Operators", The Journal of Philosophy 67, pp.10071023.

Hawthorne, John (2004): Knowledge and Lotteries, Oxford: Clarendon Press.

Lewis, David (1979): "Scorekeeping in a Language Game", Journal of Philosophical Logic 8, pp.339-359.

Lewis, David (1996): "Elusive Knowledge", Australasian Journal of Philosophy 74, pp.549-567.

\footnotetext{
${ }^{13}$ MacFarlane (2005), p.213.
} 
Ludlow, Peter (2005): "Contextualism and the New Linguistic Turn in Epistemology", in: G. Preyer/G. Peter (eds.): Contextualism in Philosophy. Knowledge, Meaning, and Truth, Oxford: Oxford University Press, pp.11-50.

MacFarlane, John (2005): "The Assessment Sensitivity of Knowledge Attributions", in: T.G. Gendler/J. Hawthorne (eds.): Oxford Studies in Epistemology 1, Oxford: Oxford University Press, pp.197-233.

Stanley, Jason (2004): "On the Linguistic Basis for Contextualism", Philosophical Studies 119, pp.119-146. 